Indonesian Journal of Biotechnology, June, 2012

Vol. 17, No. 1, pp.61-68

\title{
Regression Analysis for the Identification of RAPD Markers Linked To Drought Tolerance in Sorghum
}

\author{
Paramita Cahyaningrum ${ }^{1}$, Taryono ${ }^{2 *}$, and Anto Rimbawanto ${ }^{3}$
}

\author{
${ }^{1}$ Faculty of Science and Mathematics, Universitas Negeri Yogyakarta, Yogyakarta, Indonesia \\ ${ }^{2}$ Faculty of Agriculture, Universitas Gadjah Mada, Yogyakarta, Indonesia \\ ${ }^{3}$ Center for Forest Biotechnology Research, Ministry of Forestry, Yogyakarta, Indonesia
}

\begin{abstract}
Sorghum (Sorghum bicolor) can actually withstand in dry or drought condition better than other crops, therefore it can be grown at different agroclimatic conditions and its product can be used for different purposes such as food, feed and industrial raw material. However at severe condition, the productivity will also drop drastically. The aim of this research was to identify RAPD marker linked to the drought tolerance. In this research, varieties of sorghum used as research materials were Durra, Zhengzu, the mutants of Durra and Zhengzu (from 300 Gy gamma radiation) B-100 and Zh-30, and the F2 seeds from Zh-30 x B-100 and B-100 $x$ Zh-30. Drought screening was carried out using $0.3 \% \mathrm{KI}$ during sorghum vegetative stage. DNA extraction was done using a modified CTAB method. PCR was carried out for RAPD analysis. PCR amplification products were scored and analyzed using SAS program. The result showed that potassium iodide can be used for drought screening during the vegetative stage and regression analysis using the logistic method can be used to identify RAPD markers that is linked to drought tolerance in sorghum. The logistic analysis showed that band A8-480 was linked to drought tolerance in sorghum.
\end{abstract}

Keywords : drought, molecular marker, logistic regression, sorghum

\section{Introduction}

Sorghum is the fourth most important world cereal following wheat, rice and corn. It is a staple food in the drier parts of the world such as Africa, India and also China (Zidenga, 2004). The grain can be used for flour to make bread, porridge and for brewing beer. The large juicy sweet stems are used for chewing and making syrup and sugar. Sorghum grain and straw, taken after harvesting can be used to feed cattle or other livestock. Other uses are for making brooms, fences, or starch production from cultivars with waxy endosperms (Purseglove, 1972). Sorghum has been planted in dry areas as

\section{*Corresponding author :}

Taryono,

Department of Plant Breeding, Faculty of Agriculture,

Universitas Gadjah Mada

Jl. Flora, Bulaksumur, Yogyakarta, Indonesia, 55281

E-mail : taryono@faperta.ugm.ac.id it can withstand dry condition or drought better than other crops (Carvalho et al., 2000). However, in an extreme condition sorghum can also fail to reach its optimum yield because water is an essential need.

Since sorghum can withstand dry condition, it is interesting to study the mechanism of its molecular activities. Subudhi et al. (2002) discovered that sorghum can grow in dry conditions due to its stay green characteristics. Observations showed that the stay green characteristics may be controlled by more than one gene. Yield is also another characteristic which is known to be controlled by more than one gene or polygenic and there is also epistasis and interaction with the environment (Yin et al., 2003). If more than one gene is involved then identifying or locating them becomes difficult, due to the inheritance of the characteristics cannot be easily identified from the phenotype. The quantitative trait 
is controlled by allelic differences but also affected by the environment. From the possibility of many genes involved, Kearsey and Pooney (1996) coined the term polygenes and more recently it is known as QTL (Quantitative Trait Loci).

Quantitative trait loci actually describes an area on the chromosome which is explained by linkage with one or two markers close to the QTL of a specific trait. The markers used are usually DNA markers (Gupta, 2002), because DNA marker is not affected by theenvironment. According to Mutengwa et al. (2005), molecular markers can provide a powerful tool for crop improvement. To detect molecular markers, several techniques such as hybridization, polymerase chain reaction (PCR) or based on DNA sequence can be explored (Collard et al., 2005). Random amplified polymorphic DNA (RAPD) is PCR based techniques which produce a dominant marker and can be used for many organisms without prior knowledge of its nucleotide sequence (Zidenga, 2004; Kumar, et al., 2006).

From statistical perspective, methods for QTL mapping are generally based on least square, maximum likelihood and Bayesian approaches (Wang et al., 2006). Gupta (2002) mentioned three methods to detect QTL i.e single marker analysis, simple interval mapping (SIM) and composite interval mapping (CIM). The single marker analysis is the earliest and simplest methods to detect QTL. Single marker analysis can be approached using the regression method (Haley and Knott, 1992). Kalbehdari and Robinson (2007) reported that linear regression has been able to be used with single and multiple markers.

Blum et al. (1983) developed a technique to stimulate the effect of drought stress by inhibiting current assimilation. Using small plots of wheat, a solution of magnesium or sodium chlorate with $4 \%$ active ingredient was sprayed on the plants surface. The chemical which was a desiccant killed all photosynthetic tissue including leaves, leaf sheath, glumes and awns. When plants

were devoid of chlorophyll then it could proceed grain filling only with plant reserves. Potassium iodide could also be used as it has been done in Australia (Farag, 2004).

The objective of this research was to identify RAPD markers that are linked to drought tolerance in two sorghum varieties (from ICRISAT and China), their mutant and non-mutant populations.

\section{Materials and Methods}

Materials used to identify RAPD markers linked to drought tolerance were sorghum varieties Durra which was introduced from ICRISAT and Zhengzu from China, their mutants B-100 and ZH-30 and also the $F_{2}$ generation from Zh-30 $\times$ B-100 and B-100 $x$ Zh-30 (Figure 1) to produce 50 plants that were needed for the DNA analysis. The mutants used are from the M10 generation. The mutant B-100 was used as the male parent and is more tolerant to drought, higher in plant height $(85-165 \mathrm{~cm})$ and produced yellowish grain. The mutant $\mathrm{Zh}-30$ was used as the female parent and was less tolerant to drought, shorter $(80-130 \mathrm{~cm})$ and produced white grains better for human consumption.

A

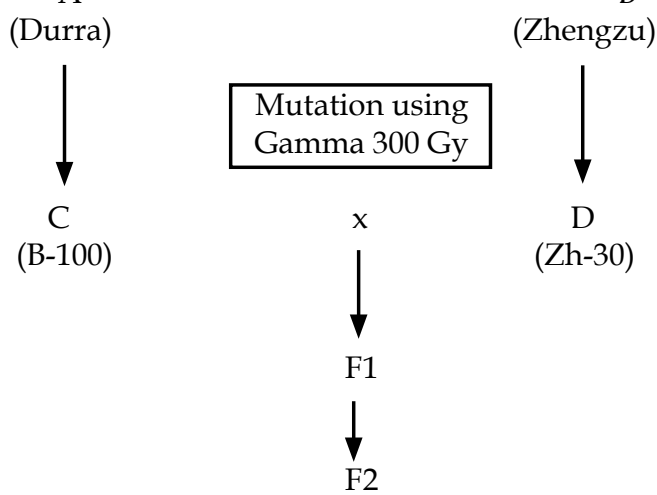

(Seeds from Centre for Application of Isotope and Radiation Technology of Indonesia)

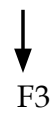

(Seeds used to identify RAPD markers linked to drought tolerance in sorghum)

Figure 1. A diagram of plant materials used in the research 
The sorghum varieties have been used by PATIR-BATAN (The Center for application of Isotope and Radiation-National Nuclear Energy Centre) for plant breeding program using mutation. Mutation was induced using Gamma ray from Cobolt-60.

The F2 population that were used for this reaearch consisted of 12 population (E-P). Those 12 population were from crosses of Zh-30 x B-100 and B-100 x Zh-30. Population with codes $E$ - $M$ were from crosses of $Z$ h-30 $x$ B-100 and N - P were from crosses of B-100 $x$ Zh-30.

\section{Evaluation of drought tolerance}

The plant materials used in this experiment were non-mutant Durra (A), non-mutant Zhengzu, mutant Durra $(C)$ and mutant Zhengzu (D). The seeds were planted in plots and arranged in completely randomized design. Treatment with potassium iodide (KI) at $0.3 \% \mathrm{w} / \mathrm{v}$ ) was carried out on the sorghum leaves at the vegetative stage or 5 weeks old plant by spraying a KI solution and irrigation was kept normal. The selection criteria for tolerant and non-tolerant plants was observed from the change in the colour of leaves. If the leaves turned brown then the plant is noted as non-tolerant. If the leaves turned yellow then the plant is tolerant. A minimum of 50 plants were observed and used for the DNA analysis.

\section{DNA analysis}

DNA was isolated from 3-4 week old plants using a modified CTAB (Cetyl trimethyl Ammonium Bromide) method. The leaves were cut for samples $(85 \mathrm{mg})$ and only one replication was sampled for DNA extraction. The DNA was purified using Geneclean® III kit (MP Biomedicals) and it was quantified using GeneQuant to measure the amount of extracted DNA. Dilution was done to obtain a final DNA concenration of $2.5 \mathrm{ng} / \mu \mathrm{l}$ for PCR analysis.

The PCR reaction was done with a total volume of $10 \mu \mathrm{l}$ for each sample using the PCR kit AmpliTaq®DNA Polymerase Stoffel
Fragment (Applied Biosystem). The six RAPD primers consisted of Proligo A8, A13, A20, D3, B7, and T14 were used to amplify DNA template. Amplification was done using a PCR machine Perkin Elmer 9600. Initial heating was done at $94^{\circ} \mathrm{C}$ for $3 \mathrm{~min}$, incubation at $95^{\circ} \mathrm{C}$ for $1 \mathrm{~min}$, then followed by 45 cycles with each cycle at $94^{\circ} \mathrm{C}$ for $30 \mathrm{sec}$, annealing at $37^{\circ} \mathrm{C}$ for $30 \mathrm{sec}$ and elongation at $72^{\circ} \mathrm{C}$ for $1 \mathrm{~min} 30$ sec followed by final elongation at $72^{\circ} \mathrm{C}$ for 7 min.

To analyze the PCR product, DNA cocktails were electrophored on the agarose gel. The gel was made with $76 \mathrm{ml}$ Psd $\mathrm{H}_{2} \mathrm{O}, 1.4 \mathrm{~g}$ agarose $(1.75 \%)$ and $4 \mathrm{ml} 20 \times \mathrm{TBE}$ buffer which was a mix of $0.45 \mathrm{M}$ tris- $\mathrm{HCl} \mathrm{pH} 8,0.45 \mathrm{M}$ boric acid, and 20mM EDTA.The mixture was then diluted properly through warm boiling and when the solution became warm, it was added with $5 \mu$ lethidium bromide. The electrophoresis buffer was made from $5 \mathrm{l}$ of $\mathrm{H}_{2} \mathrm{O}, 250 \mathrm{ml}$ of $20 \mathrm{X}$ TBE and $250 \mu \mathrm{l}$ of ethidium bromide. Electrophoresis was done after adding $2 \mu 1 \mathrm{GL} 3$ in each well containing amplified DNA from the PCR. As a marker, $10 \mu \mathrm{l}$ of $100 \mathrm{bp}$ DNA ladder was used. Electrophoresis was carried out for $2.5 \mathrm{~h}$ at $120 \mathrm{~V}$.

Visualization of electrophoresis product was done using the Fotodyne Image Analyzer with a UV light. Scoring of visualized bands was done by scoring 1 if the band was presence and 0 for no observable band. Scoring was done for each individual plant.

\section{Data analysis}

The scoring data was used to estimate the linkage between the RAPD markers and drought tolerance in sorghum using regression analysis of SAS program and logistic procedures (Anonym, 2002).

\section{Results and Discussion Drought experiment}

Observation of plants that were tolerant or not tolerant to Potassium Iodida (KI) was done three days after spraying because the effect of KI did not appear immediately. With this method drought tolerant sorghum could 
be differentiated from the sensitive plant due to its stay green characteristics. With such technique, to screen drought tolerant cereals, it was not neccesary to be carried out in dry condition and saves cost needed from large area of land (Tuinstra et al., 1996).

The use of KI caused a gradual loss of chlorophyll such as plants in a drought stress situation (Farag, 2004). Potassium iodide was sprayed at the vegetative stage because at this stage sorghum is tolerant to drought stress and the stress would not have an effect on yield. This was important even though yield was not one of the characteristics measured but the grains would be used again in further experiments. The use of KI simulated drought and has been used by several researchers such as Royo et al. (2008) in Triticale trujilo. Potassium iodide was given 10 days after anthesis and the reduced yield due to KI was almost the same as planted in dry condition.

According to Collard et al. (2005), the ratio expected for a dominant marker in an F2 population is 3:1 (B_:bb). The use of a dominant marker, however, could not differentiate a homozygote and heterozygote genotypes. The segregation ratio of the marker could be seen with a Punnet square.
In an F3 population, the ratio must be 3:2:3 (Zubay, 1987). By using a dominant marker the ratio became 5:3. If the gene controlling drought tolerance was controlled by a single dominant gene, then the ratio of the phenotype would be a ratio of 5 tolerant individuals : 3 non tolerant individual.

In this experiment, besides the mutant and non mutant parents, the F3 populations chosen were population $\mathrm{L}$ and $\mathrm{M}$ which showed segregation in drought tolerance (Table 1) and enough number of plants needed to carry DNA analysis. A minimum of 50 plants were needed to carry out QTL analysis. A segregation in the drought tolerant characteristics or a ratio that was not according to Mendelian ratio might be due to interaction of genes such as epistasis, linkage, crossing, selfing or the effect of the environment (Van Oosterom et al., 1996).

\section{Identification of RAPD marker linked to drought tolerance in sorghum}

The simplest type of population used for QTL analysis was an F2 population which was easy to construct and required a short time to produce and had all the combination of alleles from the parent.In this experiment, the F3 populations were used because the

Table 1. Drought tolerance segregation based on $0.3 \%$ KI treatment

\begin{tabular}{ccccc}
\hline \hline Population & Total number of plants & $\begin{array}{c}\text { Number of tolerant } \\
\text { plants }\end{array}$ & $\begin{array}{c}\text { Number of non } \\
\text { tolerant plants }\end{array}$ & $\begin{array}{c}\text { Ratio tolerant :non } \\
\text { tolerant plants }\end{array}$ \\
\hline A & 270 & 260 & 10 & $26: 1$ \\
B & 105 & 0 & 105 & $0: 105$ \\
C & 200 & 164 & 36 & $5: 1$ \\
D & 16 & 0 & 16 & $0: 16$ \\
E & 36 & 0 & 36 & $0: 36$ \\
F & 100 & 92 & 8 & $12: 1$ \\
G & 73 & 55 & 18 & $3: 1$ \\
H & 17 & 10 & 7 & $10: 7$ \\
I & 58 & 0 & 58 & $0: 58$ \\
J & 42 & 0 & 42 & $0: 42$ \\
K & 26 & 17 & 9 & $17: 9$ \\
L & 270 & 230 & 40 & $6: 1$ \\
M & 125 & 119 & 6 & $20: 1$ \\
N & 11 & 8 & 3 & $8: 3$ \\
O & 15 & 8 & 7 & $0: 3$ \\
P & 3 & 0 & 3 & \\
\hline
\end{tabular}


number of seeds in the F2 populations were not enough for a QTL analysis which must be more 50 individual per population (Collard et al., 2005). However, F3 population have been known to be used as evaluation for F2 plants. Gupta (1996) mentioned progeny test of F2 individuals (F3 population) could still be used in making maps when the phenotype did not reflect genotype such as disease resistance or other characteristicss which were polygenically controlled.

PCR analysis using primer A8 showed a specific band in the durra population. Mutant Durra can be identified using primer A13 with the presence of bands at $480 \mathrm{bp}, 450$ bp and $420 \mathrm{bp}$ while mutant Zhengzu had a specific band at $380 \mathrm{bp}$ (Figure 2). Using primer A20, a band at 650 bp showed for the mutant Durra population while primer D3 showed a specific band at 520 bp for mutant Zhengzu and can be seen in its F3 population. Primer B7 showed a specific band at $650 \mathrm{bp}$ for mutant Zhengzu and $420 \mathrm{bp}$ for mutant Durra which could be used to differentiate individuals in the F3 population. Primer T14 showed a band at $420 \mathrm{bp}$ which occured only in Zhengzu population.

There were different methods for QTL mapping (Wang et al., 2006). The simplest method was based on linear regression which can identify the association of phenotypic trait with marker classes by contrasting the mean of marker types, therefore linear regression approach seems very similar to analysis of variance (Kearsey, 1998). Such methods did not locate the QTL but simply confirm that the "eyeballed" location indicated a real effect. Logically, if the marker and the QTL were on different chromosomes, there will be no regression, but if they were on the same chromosome, the regression will be significant and show that the marker was close to the QTL. The easiest way to evaluate the fittest of the regression would be from the coefficient of determination $\left(R^{2}\right)$. With a regression approach of RFLP markers, Masood et al. (2004) showed several markers linked to some agronomic characteristics in rice.

Table 2. Coefficient of determination regression equation for each primer

\begin{tabular}{cc}
\hline \hline Primer & $\begin{array}{c}\text { Coefficient of determination } \\
\left(\mathrm{R}^{2}\right)\end{array}$ \\
\hline A8 & 0.4237 \\
A13 & 0.3805 \\
A20 & 0.3923 \\
D3 & 0.3248 \\
B7 & 0.2555 \\
T14 & 0.2596 \\
\hline
\end{tabular}

Primer A8 showed the highest coefficient of determination of 0.4237 . It meant that $42.37 \%$ of the variation in drought tolerance can be explained by the bands from amplicon bands of primer A8. The lowest value occured

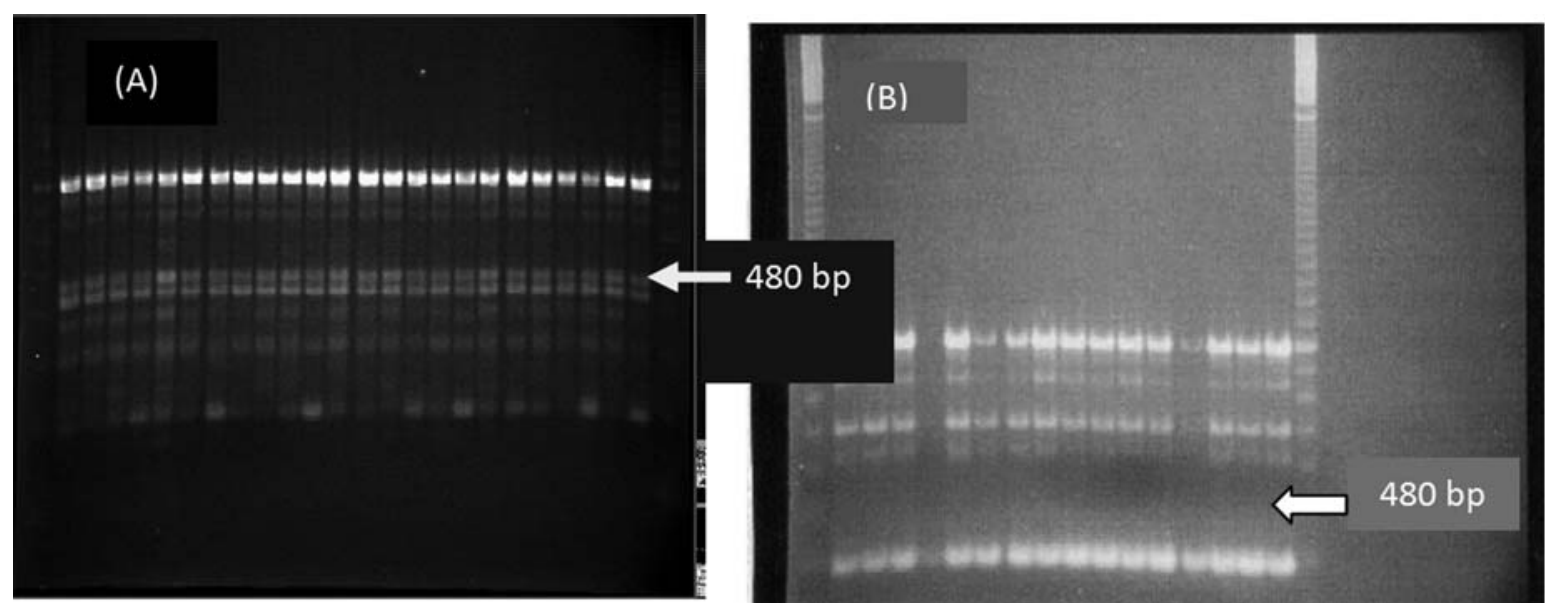

Figure2. Amplification product of primer A8 (A) B-100 (B) Zh-30 (Note : arrow showing specific band at 480bp which is monomorphic for the drought tolerant mutant B-100) 
with $B 7$ with $\mathrm{R}^{2}=0.2555$. According to the $\mathrm{R}^{2}$ value, primer $A 8$ could be more likely used as a marker for drought tolerance in sorghum (Table 2). The correlation between markers and quantitative characteristics could also be observed from its regression coefficient (b) for each marker. Regression analysis based on the model :

$$
Y=a+b 1 X 1+b 2 X 2+\ldots b j X j \ldots b n X n+d+e
$$

where $b$ were partial regression coefficients which show a relationship between variable $Y$ and $X_{i}, d$ was the residual effect and $e$ wass error from $Y$ due to variation in the environment (Virk et al., 2009).

According to Xu et al. (1998), many characteristicss in plants and animals which were economically important were expressed in binary forms. Binary characteristics which cannot be explained by Mendelian inheritance were called complex binary traits and could be explained using the probit model. In a probit model, the residual error was assumed to be in normal distribution while logistic regression used a maximum likelihood estimation after transforming the dependent variable into a logit variable. In this experiment both the regression method and the maximum likelihood method were used to find out the relationship between markers and drought tolerance in sorghum.

Regression analysis for QTL mapping have been used by many researchers such as Haley and Knott (1992) using F2 ppopulation, Rebai (1997) and Xu et al.(2005) using binary data. The results all showed that simple regression method was similar to using a maximum likelihood or probit model. From the six primers used (A8, A13, A20, D3, B7, T14) which produced 96 polymorphic bands or markers then could be used to search RAPD markers linked to drought tolerance in sorghum using the stepwise program. Using the proc reg step in SAS as it has been done by Haley and Knott (1992), marker $480 \mathrm{bp}$ from primer A8 showed the most significant chance of being a marker for drought tolerance in sorghum. A similar result showed using the proc logistic step in SAS version 9 (Table 3 ).

The estimates (b) or the regression coeffiecients which were significant (from all 96 bands produced) in two markers or bands from primer A8 at $700 \mathrm{bp}$ and $480 \mathrm{bp}$. The estimate or the value of $b$ was larger in $480 \mathrm{bp}$ which showed that this band could explain better or could detect more accurately the drought tolerance characteristics $(Y)$ in sorghum.

Table 3. Result from Maximum Likelihood Estimation using proc log step of SAS

\begin{tabular}{ccccc}
\hline \hline Parameter & df & $\begin{array}{c}\text { Estimate } \\
(\mathrm{b})\end{array}$ & $\begin{array}{c}\text { Standard } \\
\text { Eror }\end{array}$ & Pr $>$ ChiSq \\
\hline A8-700 bp & 1 & 1.6034 & 0.3258 & $<.0001$ \\
A8-480 bp & 1 & 2.3959 & 0.3671 & $<.0001$
\end{tabular}

The result from the logistic regression analysis using stepwise program showed that the linear model for the relationship between drought tolerance characteristics ( $Y$ variable) and the bands from each primer ( $\mathrm{X}$ variable) for Durra and Zhengzu sorghums was:

$$
\mathrm{Y}=-2.3409+1.6034(\mathrm{~A} 8-700 \mathrm{bp})+2.3959(\mathrm{~A} 8-480 \mathrm{bp}) \text {. }
$$

It showed that the use of A8-400 bp band would provide more chance to screen drought tolerant lines than A8-700b, although both alleles (marked by the bands at A8-480 and A8-700) could be situated at the same chromosome for drought tolerance. A8-480 bp band was probably located more close to the QTL due to a higher coefficient of 2.3959 show that it can be used as a stronger marker for the tolerant variety. This result is the same as in Figure 2 where a specific band occur at 480 for tolerant variety B-100 (specific band showed by arrow).

Although this finding has not been applied to assist selection, regession approach from practicle point of view would be the approach of choice because it offered greater speed and flexibility (Knott, 2005). It was relatively fast to be implemented, easy to be generalized to experimental population and 
easy to include cofactor. Regression approach showed good robustness properties against non-normality and the estimation procedure was also distribution free (Rubai, 1997). Regression based QTL will continue to play a role, given its status as a simple framework in which to fit complicated model (Knott, 2005).

The use of molecular marker such as RAPD would be more benefit to assist selection because molecular markers in general were scattered through the genome and their associations with various agronomic traits could be useful to help crop improvement program (Muthusamy et al., 2008). Tanksley (1993) mentioned five inherent properties of molecular markers that was distinguished from morphological markers. The phenotype of most morphological markers could only be determined at the whole plant level, whereas molecular loci could be assayed at the whole plant, tisuue, and cellular level. Allele frequency tended to be much higher at the molecular loci compared with morphological markers. Alleles at morphological loci interacted in dominantrecessive manner that limit the identification of heterozygotes genotypes, while some molecular loci exhibited a codominant made of inheritance. Only fewer espistatic and pleitropic effects are observed with molecular markers and large number of polymorphic markers could be generated and monitored in a single cross only. It was believed that the use of molecular marker can speed up new cultivar development.

From this experiment, it could be concluded that screening for drought tolerance using $0.3 \%$ KI on sorghum was efficient because screening could be done three days after treatment and not dependent on the season or weather, and RAPD could be used to observe variation in sorghum and (3) QTL analysis using regression can be used to find specific marker for drought tolerance in sorghum.

\section{Acknowledgements}

We are thankful to all staff members of Centre for Application of Isotope and
Radiation Technology of Indonesia, Jakarta especially the Institute of Plant Breeding for providing seed materials.

\section{References}

Anonym. 2002. Guides for Personal Computers. Version 9. SAS Institute Inc. Cary. North Carolina. USA

Blum, A., Ebercon, A. Sinmena, B. Goldenberg H. Gerechter-Amitai, Z.K. and Grama, A. 1983. Drought resistance reactions of wild emmer (Triticum dicoccoides) and wild emmer $x$ wheat derivatives. Proceedings 6th International Wheat Genetics Symposium. p.433

Carvalho, L.F., Medeiras Filho, S. Rossetti, A.G. and Teofilo.E.M.2000.Osmoconditionning in sorghum seed. Rewvista Brasileira de Sementes, 22, 185-192

Collard, B.C.Y., Jahufer, M.Z.Z. Brouwer, J.B. and Pang, E.C.K. 2005. An introduction to markers, quantitative trait loci (QTL) mapping and marker-assisted selection for crop improvement: The basic concepts. Euphytica, 142, 169-196..

Farag, K.F.M. 2004. The Inheritance and Molecular Mapping of Genes for Postanthesis Drought Tolerance (PADT) in Wheat. Dissertation

Gupta, P.K. 2002. Molecular markers and QTL analysis in crop plants. Curr. Sci., 83, 113-114

Haley, C.S., and Knott, S. A. 1992. A simple regression method for mapping quantitative trait loci in line crosses using flanking markers. Heredity, 69, $315-324$.

Kalbehdari, D.,and Robinson, J.A.B. 2007. QTL mapping using multiple markers simultaneously. Am. J. Agri. Biol. Sci., 2, 195-201

Kearsey, M.J. 1998. The principles of QTL analysis (a minimal mathematics approaches). J. Exp. Botany, 49, 16191623

Kearsey, M.J., and Pooney H.S. 1996. The genetical analysis of quantitative traits. Chapman and Hall. London. 
Knott, S.A. 2005. Regression based quantitative trait loci mapping: robust, efficient and effective. Phil. Trans. Royal Soc. Biol. Sci., 360, 1435-1442

Kumar, S., Prasad, K.V. and Choudhary, M.L. 2006. Detection of genetic variability among Chrysanthemum radiomutants using RAPD markers. Curr. Sci., 90, 1108-1113

Masood, M.S., Seiji, Y. Shinwai, Z.K. and Anwar , R. 2004. Mapping quantitative trait loci (QTL) for salt tolerance in rice (Oryza sativa L.) using RFLPs. Pakist. J. Botany, 36: 825-834

Mutengwa, C.S., Tongoona,P. B., and SitholeNiang I. 2005. Genetic studies and a search for molecular markers that are linked to Striga asiatica resistance in sorghum. Afr. J. Biotech., 4, 1355-1361

Muthusamy, S., Kanagarajan, S. and Ponnusamy, S. 2008. Efficiency of RAPD and ISSR markers system in accessing genetic variation of rice bean (Vigna umbellata) landraces. Electr.J. .Biotech.11, 1-10 (http:/ / www.ybiotechnology.info)

Purseglove, J.W. 1972. Tropical crops: Monocotyledons. John Wiley \& Sons. New York.

Rebai, A. 1997. Comparison of methods of regression interval mapping in QTL analysis with non-normal traits. Gen. Res., 65, 68-74

Royo, C., Abaza, M. Cantero, C. Caldero,A. Ramos, J.M. and Garcia del Moral, L.F. 2008. Linking between the effect of drought and terminal water-stress simulated by a senescing agent in triticale. J. Agro. Crop Sci., 176(1), 31-38

Subudhi, P.K., Nguyen, H.T. Gilbert, M. L. and Rosenow, D.T. 2002. Sorghum improvement : past achievements and future prospects. In: crop improvement: challenges in the twenty-first century. Kang (ed). The Haworth Press, Inc. New York. 109 - 160.

Tanksley, S.D. 1983. Molecular markers in plant breeding. Plant Mol. Biol. Rep., $1,3-8$
Tuinstra, M.R., Grote,E.M., Goldsburgh, P.B. and Ejeta G. 1996. Identification of quantitative trait loci associated with pre-flowering drought tolerance in sorghum. Crop Sci., 36, 1337-1344

Tuinstra, M.R., Ejeta, G. and Goldsburgh P. 1998. Evaluation of near-isogenic lines contrasting for QTL markers associated with drought tolerance. Crop Sci., 38, 835-842

Wang, J., Wan, X.Y., Crossa, J. C., Crouch,J. ,Weng, J.F., Zhai,H., and Wan, J.M. 2006. QTL mapping of grain length in rice (Oryza sativa L.) using chromosome segment substitution lines. Gen.Res. Cambridge, 88, 93 - 104

Van Oosterom, E.J., Jayachandran, R. and Bidinger F.R. 1996. Diallel analysis of the stay-green trait and its components in sorghum. Crop Sci., 36, 549-555

Virk, P.S., Ford-Lloyd, Jackson,B.V, M.T. ,Pooni,H.S. , Clemeno, T.P. and Newbury ,H.J. 2009. Marker-assisted prediction of agronomic traits using diverse rice germplasm. http://www. irri.org/science/abstracts.

Xu, S., Yonash, N, Vallejo, R.L, Cheng, H.H. 1998. Mapping quantitative trait loci for binary traits using a heterogeneous residual variance model: an application to marek's disease susceptibility in chickens. Genetica, 104, 171 - 178.

Xu, C., Zhang, Y-M. and Xu, S. 2005. An EM algorithm for mapping quantitative resistance loci. Heredity. 94, 119-128.

Yin, X., Stam, P., Kropff, M.J., Schapendonk ,A.H.C.M. 2003. Crop modelling, QTL mapping, and their complementary role in plant breeding. Agro. J., 95, 90-98

Zidenga, T. 2004. DNA-based methods in sorghum diversity studies and improvement. ISB News Report. <http://www.isb.vt.edu/news/2004/ artspd/mar0404.pdf

Zubay, G.L. 1987. Genetics. The Benyamin /Cumming Publishing Company Inc. Massachussets.USA 